\title{
APROVEITAMENTO DA SEMENTE DE AÇAÍ PARA PRODUÇÃO DE BEBIDA À BASE DE CAFÉ
}

\author{
Lara Santana Fernandes ${ }^{1}$, Bruna Giaretta Martins², Juliana Lane Paixão², Lara Stela Mendes Lustoza², \\ Daniel Mariano Leite ${ }^{3}$
}

\begin{abstract}
RESUMO
O aproveitamento da semente de açaí em bebida à base de café é uma alternativa para a redução do impacto ambiental e para a agregação de valor ao resíduo da agroindústria de açaí. Objetivou-se com a condução do presente trabalho avaliar o aproveitamento da semente de açaí, subproduto do beneficiamento dos frutos, para a produção de uma bebida à base de café e semente de açaí. Foram feitas a torrefação e moagem da semente de açaí e de grãos de café, tendo sido analisada sensorialmente a bebida nas concentrações $(0,25,50,75$ e 100\%) de semente de açaí, foram feitas ainda análises de polifenóis da amostra da bebida de maior aceitação sensorial e das amostras controles $(0$ e $100 \%$ de semente de açaí) e de minerais da amostra da bebida de maior aceitação sensorial e das amostras controles. A análise sensorial mostrou que a amostra contendo $25 \%$ de sementes de açaí foi a de maior aceitação, mas apresentou baixos teores de polifenóis totais quando comparada com a bebida $100 \%$ café. Alguns minerais não diferiram estatisticamente em nível de $1 \%$ de probabilidade. A adição de sementes de açaí, em baixas concentrações, na bebida à base de café mostrou ser uma alternativa viável para aproveitamento desse resíduo.
\end{abstract}

Palavras-chave: análise sensorial, grãos de café, pós-colheita

\section{ABSTRACT \\ USE OF AÇAI SEEDS TO PREPARE COFFEE BASED DRINK}

The use of açai seed in coffee-based drink is proposed as an alternative to reducing the environmental impact and for adding value to açai agro-industry waste. The objective of the conduct of this study was to evaluate the use of the seed of acai, a byproduct of the processing of fruits, to produce a coffee-based drink and acai seed. We performed the roasting and grinding the açai seeds and coffee grains, we analyzed the drink sensory on concentrations $(0,25,50,75$ and $100 \%$ ) from açai seed, performed the analysis of polyphenols from sample drink better sensory acceptance and control samples ( 0 and $100 \%$ açai seed) and did the analysis of minerals in the sample of drink that had the greater acceptability and of control samples. The sensory analysis showed that the sample containing $25 \%$ açai seeds was better received, but had lower content of total polyphenols compared to drink $100 \%$ coffee. Some minerals do not differ ststiscally at $1 \%$. The addition of seeds at low concentrations in acai-based drink coffee proved to be a viable alternative to use of this waste.

Keywords: sensory analysis, coffee grains, post harvest

\section{Recebido para publicação em 10/09/2010. Aprovado em 01/09/2011.}

1- Eng. de Alimentos, Mestranda em Engenharia Agrícola, UFV/Viçosa-MG, lara.fernandes@ufv.br

2- Eng. de Alimentos, Departamento de Tecnologia de Alimentos, UFV/Viçosa-MG

3- Lic. em Ciências Agrícolas, Doutorando em Engenharia Agrícola, UFV/Viçosa-MG

\section{REVENG} 510-515 p. 


\section{INTRODUÇÃO}

A palmeira Euterpe oleraceaMart., conhecida como açaizeiro, pode ser considerada a palmeira de maior importância econômica, social e cultural da região norte do Brasil, destacando-se o Estado do Pará como o maior produtor e consumidor ( NASCIMENTO et al., 2008; NETO et al., 2011).

O açaí constitui a base da alimentação cotidiana de diversas famílias da região Norte do Brasil, oferecendo grande disponibilidade de resíduos (SILVA et al., 2004). Segundo o IBGE (2010), o Brasil produziu em 2009, aproximadamente, 119.000 toneladas de frutos de açaí, e cerca de $90 \%$ deste volume corresponde aos resíduos gerados após o processamento agroindustrial do fruto.

Os resíduos do fruto são constituídos basicamente de semente e de fibras. Apesar de ser uma fonte de material lignocelulósico renovável, este resíduo representa atualmente um grave problema ambiental (RODRIGUES et al., 2006).

Empresas amazonenses têm desenvolvido tecnologias específicas para o beneficiamento da semente, transformando-a em matéria-prima para a fabricação de inúmeros produtos, como ração animal, café, óleo comestível, pães, produtos fitoterápicos, móveis, compensados, componentes de carros e barcos. Já patenteado, o "A4", como é conhecido o produto beneficiado, começa a ser utilizado pelas indústrias locais com a intenção de massificar o seu uso (VASCONCELOS, 2005).

Denomina-se semente de açaí, o fruto despolpado, que representa $83 \%$ do fruto, sendo obtido no ato da extração da polpa para preparação do suco de açaí. O poder calorífico da semente, obtido em laboratório, é, em média de $4.505 \mathrm{kcal} \mathrm{kg}^{-1}$, e o potencial energético gira em torno de $40.800 \mathrm{MWh} /$ mês (SILVA et al., 2004). No entanto, não existem referências sobre o aproveitamento dessas sementes para fins alimentícios.

Atualmente, o café tem grande importância na economia mundial. Seu mercado internacional movimenta anualmente recursos na ordem de 15 bilhões de dólares. O café é a bebida mais consumida no mundo e o segundo maior mercado depois do petróleo. Em função deste alto consumo mundial, a partir de anos mais recentes, as pesquisas relacionadas às atividades biológicas do café torrado foram intensamente estimuladas (ABIC, 2010).

Os valores dos constituintes solúveis em água presente no café são: polímeros fenólicos $8 \%$, polissacarídeos $6 \%$, ácidos clorogênicos $4 \%$, minerais $3 \%$, cafeína $1 \%$, ácidos orgânicos $0,5 \%$, açúcares $0,3 \%$, lipídeos $0,2 \%$ e aroma $0,1 \%$. Os ácidos clorogênicos constituem os principais compostos fenólicos do café, que são altamente significativos para o sabor e aroma da bebida. A ingestão de ácidos clorogênicos estimula a secreção de ácido clorídrico no estômago (ARNAUD et al., 1988).

A utilização da semente do açaí como ingrediente da bebida de café é uma interessante alternativa, uma vez que agrega valor ao resíduo, reduz os custos necessários para tratamento e destino destes resíduos e contribui para redução do impacto ambiental dentro de um sistema de desenvolvimento sustentável.

Sendo assim, objetiva-se com o presente trabalho avaliar o aproveitamento sustentável da semente de açaí, subproduto do beneficiamento dos frutos, para produção de uma bebida à base de café e semente de açaí, tendo como objetivos específicos:

- Análise sensorial da bebida de café com diferentes concentrações $(0,25,50,75$ e $100 \%)$ de semente de açaí;

- Análise de polifenóis da amostra de bebida de café com semente de açaí de maior aceitação sensorial e das amostras controles (0 e 100\% de semente de açaí); e

- Análise de minerais da amostra de bebida de café com semente de açaí de maior aceitação sensorial e das amostras controles (0 e 100\% de semente de açaí).

\section{MATERIAL E MÉTODOS}

Foram utilizados café torrado adquirido no comércio local e sementes de açaí (Euterpe oleracea Mart.) provenientes do estado do Pará. As sementes foram transportadas em sacos de polietileno até o Departamento de Tecnologia de Alimentos da Universidade Federal de Viçosa UFV, sendo mantidas em temperatura ambiente até a posterior utilização. 
As sementes de açaí foram torradas e moídas no Laboratório do Centro Nacional de Treinamento em Armazenagem - Centreinar.

Foram torradas 3,6 kg de sementes previamente limpas, no torrador (Rod Bel S.A), a $120{ }^{\circ} \mathrm{C}$ por trinta minutos. Os grãos torrados de café e de semente de açaí foram moídos no equipamento de moagem MAHLKONIG, na granulometria 2.

Foram utilizados sementes de açaí (SA) e grãos de café (GC) em cinco diferentes formulações, de acordo com as seguintes proporções: $0 \% \mathrm{SA} \mathrm{e} 100 \%$ GC; $25 \%$ SA e $75 \%$ GC; $50 \%$ SA e $50 \%$ GC; $75 \%$ SA e $25 \%$ GC; e $100 \%$ SA e $0 \%$ GC.

As amostras de café com semente de açaí torrada e moída foram preparadas a fim se obter uma infusão concentrada, utilizando cerca de $40 \mathrm{~g}$ de pó (café com semente de açaí) e $250 \mathrm{~mL}$ de água fervente, à temperatura de $95{ }^{\circ} \mathrm{C}$, utilizando-se suporte de filtro plástico sobre recipiente coletor e papel de filtro comum para a filtragem.

A análise sensorial foi realizada utilizando cinco amostras de bebida de café e semente de açaí em diferentes concentrações.

A avaliação foi feita utilizando $30 \mathrm{~mL}$ de cada amostra da bebida servida em copos descartáveis previamente codificados com número de três dígitos. As amostras foram avaliadas à temperatura média de $60{ }^{\circ} \mathrm{C}$ por 50 julgadores não treinados, sendo 28 homens (56\%) e 22 mulheres (44\%).

A faixa etária predominante para homens e mulheres foi de 15 a 35 anos. Utilizou-se escala hedônica de nove pontos, variando de gostei extremamente (9) a desgostei extremamente (1), sendo avaliada a impressão global da bebida. A avaliação foi feita em condições laboratoriais, em que as cinco amostras foram apresentadas e analisadas de forma monádica e randomizada por potenciais consumidores, de modo que cada ordem possível ocorreu em um mesmo número de vezes ao se realizar a análise da bebida em questão (MONTEIRO e TRUGO, 2005).

Os consumidores, que eram os julgadores, receberam uma bandeja contendo a amostra da bebida previamente adoçada, água para enxágue da boca, ficha de avaliação das amostras, além de instruções quanto ao procedimento de análise das amostras (MINIM, 2006).

As fichas de respostas preenchidas pelos julgadores foram organizadas, e a escala nominal foi transformada em valores numéricos, de acordo com a Tabela 1, para a análise dos resultados (MINIM, 2006).

Os dados referentes à aceitação das cinco amostras avaliadas pelos 50 provadores foram submetidos à análise de regressão linear.

O conteúdo fenólico total foi determinado em triplicata pelo ensaio com o reagente Foling-Denis, segundo metodologia citada por Shahidie Naczk (1995), com algumas modificações. A análise foi realizada na amostra de maior aceitabilidade sensorial ( $25 \%$ de semente de açaí) e nas amostras de 0 e $100 \%$ de semente, utilizadas como controle. A cada $1 \mathrm{~mL}$ de cada amostra $0 \%, 25 \%$ e $100 \%$ de semente de açaí, foram adicionados $7,5 \mathrm{~mL}$ de água destilada e $0,5 \mathrm{~mL}$ do reagente de Foling-Denis, a solução foi agitada, permanecendo 3 minutos em repouso ao abrigo da luz.

Em seguida, adicionou-se $1 \mathrm{~mL}$ de solução saturada de bicarbonato de sódio. A solução permaneceu 1 hora em repouso no escuro. A solução "branco" foi preparada nas mesmas condições do extrato, substituindo-se o volume de extrato fenólico pelo volume dos solventes contidos no extrato

Tabela 1. Exemploplo de decodificação em escala hedônica verbal de nove pontos

\begin{tabular}{lc}
\hline \multicolumn{1}{c}{ Classificação na escala } & Escore \\
\hline Gostei extremamente & 9 ou 4 \\
Gostei muito & 8 ou 3 \\
Gostei moderadamente & 7 ou 2 \\
Gostei ligeiramente & 6 ou 1 \\
Indiferente & 5 ou 0 \\
Desgostei ligeiramente & 4 ou -1 \\
Desgostei moderadamente & 3 ou -2 \\
Desgostei muito & 2 ou -3 \\
Desgostei extremamente & 1 ou -4 \\
\hline
\end{tabular}


fenólico, na proporção de sistema extrator: água de 2:3 (v/v).

As leituras espectrofotométricas da amostra e do branco foram realizadas a $750 \mathrm{~nm} \mathrm{em}$ espectrofotômetro UV-1601 PC Shimadzu, em cubetas de quartzo. A quantificação de polifenóis totais foi feita com base na curva padrão de ácido gálico P. A., preparada com soluções do padrão, variando entre 25 e $150 \mathrm{mg} \mathrm{L}^{-1}$. O conteúdo fenólico total foi expresso em "ácido gálico equivalente" (g de ácido gálico equivalente/ $100 \mathrm{~mL}$ da bebida).

As análises de minerais foram realizadas no Laboratório de Mineralogia do Departamento de Solos da Universidade Federal de Viçosa.

As amostras de bebida de 0, 25 e 100\% de sementes de açaí torradas e moídas tiveram os teores de minerais quantificados pelo método de espectrofotometria de absorção atômica, tendo sido possível determinar os teores de $\mathrm{K}, \mathrm{Ca}, \mathrm{Mg}$, Fe e P.

Foram pesadas $0,5 \mathrm{~g}$ das amostras, que foram transferidas para ostubos de digestão.Acrescentaramse $10 \mathrm{~mL}$ de ácido nítrico concentrado, seguindo por mistura. Após repouso de 2 horas, os tubos foram colocados no bloco digestor e a temperatura foi elevada até $150{ }^{\circ} \mathrm{C}$. Depois da evaporação da maior parte do ácido e do clareamento da solução, os tubos foram retirados do bloco e acrescentou-se $1 \mathrm{~mL}$ de ácido perclórico.

Os tubos foram colocados novamente no digestor e a temperatura foi elevada até $210{ }^{\circ} \mathrm{C}$. A digestão chegou ao fim quando a solução se tornou incolor com o aparecimento de uma fumaça branca e densa do ácido perclórico. Em seguida, a amostra foi resfriada e foram adicionados $10 \mathrm{~mL}$ de água destilada, com o tubo sob agitação, para a lavagem interna.

A leitura dos minerais foi feita no aparelho de absorção atômica modelo Spectra 220SS marca Varian, com gás acetileno, nos comprimentos de onda: 422,$7 ; 285,2 ; 248,3$ e $725 \mathrm{~nm}$.

\section{RESULTADOS E DISCUSSÃO}

Para a análise dos resultados obtidos, foi ajustada a regressão linear das médias dos escores obtidos no teste de aceitação com a porcentagem de semente de açaí na bebida (Figura 1).

Observa-se, na Figura 1, efeito negativo da porcentagem de semente de açaí presente na bebida em relação às médias dos escores obtidos no teste de aceitação. De acordo com esta análise, nota-se que a partir do escore seis, cujo termo hedônico se refere a "Gostei ligeiramente", a amostra da bebida é considerada aceitável, sendo assim, é possível uma composição de até $22 \%$ de semente de açaí na bebida.

A partir do resultado do teste de aceitação, a bebida com $25 \%$ de semente de açaí e as bebidas com 0 e $100 \%$ de semente de açaí(controle) foram caracterizadas por meio das análises de polifenóis totais e minerais $(\mathrm{K}, \mathrm{Ca}, \mathrm{Mg}, \mathrm{Fe}, \mathrm{P})$, sendo que as amostras de 50 e $75 \% 75 \%$ de semente não apresentaram boa aceitabilidade pelos julgadores e, portanto, não foram caracterizadas (polifenóis e minerais).

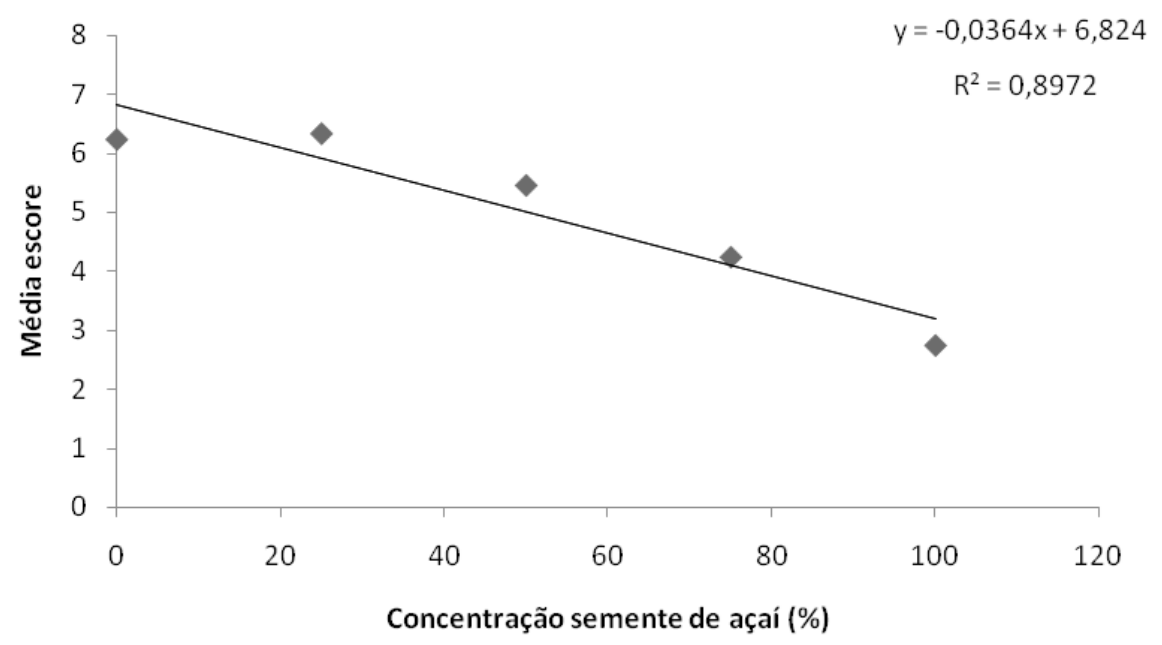

Figura 1. Relação entre a média obtida no teste de aceitação e as proporções das amostras de bebida de café com semente de açaí. 
Na Figura 2 é representado o comportamento da curva padrão.

Em seguida, foram feitas as leituras espectofotométricas para as bebidas contendo 0 , 25 e $100 \%$ de semente de açaí (Tabela 2).

Pode-se observar que a amostra com 25\% de semente de açaí e $75 \%$ de café contém aproximadamente $86 \mathrm{mg} \mathrm{L}^{-1}$ de polifenóis expressos em ácido gálico, o que é aceitável, já que em comparação com a bebida de $0 \%$ de semente de açaí (bebida de café), ela apresentou apenas uma redução de $15,7 \%$ em polifenóis totais.

Por outro lado, a bebida com $100 \%$ de semente de açaí apresentou quantidade insignificante de polifenóis totais presentes comparados à quantidade presente na bebida com $0 \%$ de semente de açaí.

Os resultados obtidos na análise de minerais pelo método de espectrofotometria de absorção atômica das amostras de 0,25 e $100 \%$ de semente de açaí se encontram na Tabela 3.

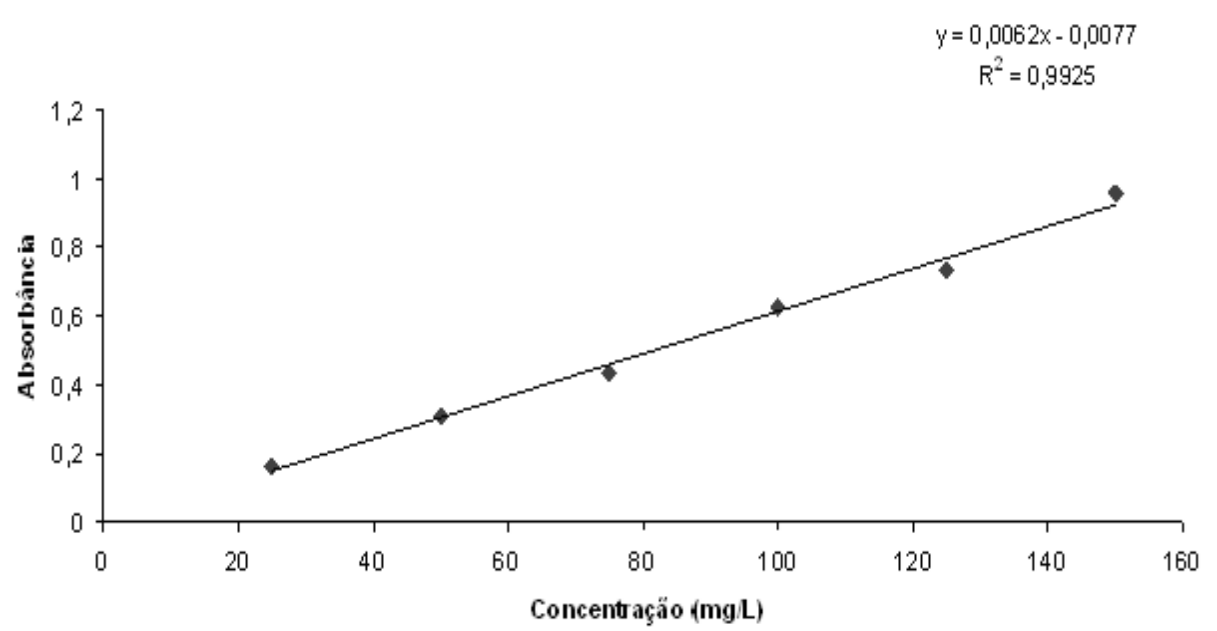

Figura 2. Curva padrão analítica do ácido gálico para determinação de polifenóis.

Tabela 2. Leituras espectofométricas para as amostras de 0,25 e 100\% de sementesde açaí em $725 \mathrm{~nm}$

\begin{tabular}{cccc}
\hline Concentração de semente de açaí (\%) & $\begin{array}{c}\text { Absorbância } \\
\text { média }\end{array}$ & Desvio Padrão & $\begin{array}{c}\text { Concentração } \\
\text { polifenóis(mg L }\end{array}$ \\
\hline 0 & 0,624 & 0,037 & 101,89 \\
25 & 0,525 & 0,020 & 85,92 \\
100 & 0,097 & 0,003 & 16,89 \\
\hline
\end{tabular}

Tabela 3. Resultados da análise de minerais $\mathrm{K}, \mathrm{Ca}, \mathrm{Mg}$, Fe e $\mathrm{P}$

\begin{tabular}{cccccc}
\hline $\begin{array}{c}\text { Concentração de } \\
\text { semente de açaí (\%) }\end{array}$ & $\mathrm{K}(\%)$ & $\mathrm{Ca}(\%)$ & $\mathrm{Mg}(\%)$ & $\mathrm{Fe}(\mathrm{mg} / \mathrm{Kg})$ & $\mathrm{P}(\%)$ \\
\hline \multirow{2}{*}{0} & 6,72 & 0,11 & 0,22 & 150 & 0,21 \\
& 6,95 & 0,11 & 0,23 & 158 & 0,2 \\
& 6,56 & - & 0,22 & - & 0,2 \\
\hline \multirow{2}{*}{25} & 5,65 & 0,09 & 0,2 & 80 & 0,2 \\
& 5,86 & 0,1 & 0,21 & 100 & 0,2 \\
& - & 0,1 & - & 75 & - \\
\hline \multirow{2}{*}{100} & 0,87 & 0,05 & 0,05 & - & 0,13 \\
& - & 0,05 & 0,06 & - & 0,14 \\
& 0,93 & 0,07 & 0,05 & 50 & 0,14 \\
\hline
\end{tabular}


Tabela 4. Resultados do teste $t$ de Student para as médias do teor de minerais

\begin{tabular}{|c|c|c|c|c|}
\hline \multirow{2}{*}{ Minerais } & \multicolumn{2}{|c|}{ Médias } & \multirow{2}{*}{ G. L. } & \multirow{2}{*}{ t calculado } \\
\hline & Café & Mistura & & \\
\hline $\mathrm{K}$ & 6,74 & 5,75 & 3 & $5,96^{*}$ \\
\hline $\mathrm{Ca}$ & 0,11 & 0,096 & $2^{\mathrm{a}}$ & $4,00^{\text {n.s. }}$ \\
\hline $\mathrm{Mg}$ & 0,223 & 0,205 & 3 & $3,22^{\text {n.s. }}$ \\
\hline $\mathrm{Fe}$ & 154 & 85 & 3 & $6,70 *$ \\
\hline $\mathrm{P}$ & 0,203 & 0,2 & $2^{\mathrm{a}}$ & $1,00^{\text {n.s. }}$ \\
\hline
\end{tabular}

* Significativa ao nível de $1 \%$ de probabilidade pelo teste t de $\operatorname{Student}(\mathrm{P}<0,01)$

n.s. Não significativo ( $\mathrm{P}>0,01)$.

${ }^{\mathrm{a}}$ Graus de liberdade obtidos por Satterthwaite.

Observa-se menor teor de minerais presentes na bebida contendo $100 \%$ de semente de açaí em relação à bebida de café (Tabela 2). Já a mistura contendo $25 \%$ de semente de açaí apresentou valores próximos ao da bebida de café ( 0 de semente de açaí).

A fim de verificar se os valores médios do teor de minerais destas duas bebidas diferem entre si ao nível de $1 \%$ de probabilidade, realizou-se uma análise estatística utilizando o teste $t$ de Student (Tabela 4).

Por ter sido utilizado um valor reduzido do número de graus de liberdade para a análise estatística, houve a necessidade de realizá-la ao nívelde $1 \%$ de probabilidade.

Conforme observado, os minerais $\mathrm{K}$ e $\mathrm{Fe}$ apresentaram diferença significativa do café para a mistura de $25 \%$ de semente de açaí e $75 \%$ de grãos de café. Já os minerais $\mathrm{Ca}, \mathrm{P}$ e $\mathrm{Mg}$ não diferiram estatisticamente ao nível de $1 \%$ de probabilidade.

\section{CONCLUSÕES}

- Apesar de as sementes apresentarem aroma similar ao de café, sua aceitação sensorial ficou limitada à utilização de no máximo $22 \%$ na bebida à base de café;

- A amostra contendo $25 \%$ de sementes e $75 \%$ de café foi a de maior aceitação pelos julgadores;

- Os resultados de polifenóis totais e minerais na caracterização da bebida contendo $25 \%$ de semente de açaí mostraram que ela apresenta baixos valores de polifenóis totais e de minerais; e

- O aproveitamento da semente de açaí em bebida à base de café é uma alternativa para redução de custos necessários para disposição e tratamento desses resíduos, redução do impacto ambiental causado pelo elevado volume de resíduo gerado e para agregação de valor ao resíduo da agroindústria de açaí.

\section{REFERÊNCIAS BIBLIOGRÁFICAS}

ABIC - Associação Brasileira da Indústria de Café- Disponível em: <www.abic.com.br $>$. Acesso em: 5 maio de 2010.

ARNAUD M. J.; CLARKKE, R. J.; MACRAE, R. (Ed.) Coffee: The Metabolism of Coffee Constituents. ElsevierApplied Science, London and New York, v. 3, 41-43, 1988.

IBGE - Instituto Brasileiro de Geografia e Estatística. Produção da extração vegetal da Silvicultura, 2009. Disponível em: <www.ibge.gov.br>. Acesso em: 15 jun. 2010.

MINIM, V.P.R. Análise sensorial: estudos com consumidores. Viçosa. Editora UFV, 2006. 225p.

MONTEIRO, M. C.; TRUGO, L. C. Determinação de compostos bioativos em amostras comerciais em café torrado. Química Nova, colocar o nome da cidade a qual a revista percente, v. 28, p. 637-641, 2005.

NASCIMENTO, R.J.S.; COURI, S.; ANTONIASSI, R.; FREITAS, S.P. Composição em ácidos graxos do óleo da polpa de açaí extraído com enzimas e com hexano. Revista Brasileira de Fruticultura, Jaboticabal, v. 30, n. 2, p. 498-502, 2008.

NETO, J. T. F.; RESENDE, M. D. V.; OLIVEIRA, M. S. P. Seleção simultânea em progênies de açaizeiro irrigado para produção e peso do fruto. Revista Brasileira de Fruticultura, Jaboticabal, v. 33, n. 2, p. 532-539, 2011. 